\title{
The Changing Role of University Computing Centers: Toward Variety of Networking, Computing and Educational Services
}

\author{
Zoran Bekić \\ University of Zagreb, University Computing Centre (SRCE), Croatia
}

\begin{abstract}
What are the roles of computing centers within academic and research community today, has their time passed away and they are just dinosaurs belonging to history or their time is just coming again with new tasks, challenges and high expectations?

In this article we analyzed the needs of academic and research community in the field of information and communication technology and came to the conclusion that in the next period we should expect only further significant growth (in terms of quantity as well as variety) of those needs. Considering that fact, we foresee and discuss the range of potential roles of computing centers in an academic and research community in the near future.

Our arguments are verified through the case of University Computing Centre (SRCE) University of Zagreb, which is celebrating thirty years of successful leading in implementation of latest information and communication technologies and serving the needs of academic and research community in Croatia.
\end{abstract}

Keywords: computing centre, data centre, ICT infrastructure, ICT support, ICT education.

\section{Introduction}

Information and communication technology (ICT) is definitely recognized as one of major driving forces in any business, especially in any change, development or improvement.

Despite of the awareness of the importance of ICT and probably because of

- overall accessibility and availability of ICT,

- improvements and simplifications of user interfaces,
- decentralization and distribution of computer architecture and distribution of functioning and management of ICT infrastructure,

- possibility to effectively (at least theoretically) outsource all or part of ICT maintenance tasks

and because of all these reasons, during the past years or decades an attitude was established by many users that ICT systems are functioning autonomously and that, in case of some trouble, it would be always possible to find "somebody nearby" to help and solve the problem, or, in the "worst case", to buy one more piece of hardware or software to solve the problem.

Academic and research community is no exception to this situation. Today it is impossible to imagine any successful and effective education or research process without high involvement of ICT. On the other hand, the role of ICT teams or computing or data centers, is very often underestimated or even questioned. Their funding is often the low priority "nightmare" for university or institute managements.

What are the roles of computing centers (or centralized computing services) within academic and research community today, has their time passed away and they are just dinosaurs belonging to history or their time is just coming again with new tasks, challenges and high expectations? 


\section{Evolution of the Needs of Academic and Research Community in the Field of ICT}

At the very beginning of our information age, in the 50s and 60s of the 20th century, computers were expensive and, to a certain degree, exclusive tools, used in very few, usually emerging and highly demanding fields of science and research. Use of computers was a privilege, in the sense of having the access to computers and having the knowledge how to use them.

In the years and decades that followed, computers became just a part of much more complicated global information and communication infrastructure. During that period, several paradigms of computing were introduced: centralized computing was replaced by a distributed computing concept and client-server approach in software development. Implementation of new paradigms was dramatically pushed forward by such revolutionary developments as massive deployment of personal computers or global operation and availability of Internet.

In such circumstances, ICT is, more than ever before, an important tool in many scientific and research processes, essentially influencing effectiveness and results of those processes. Besides that, ICT infrastructure has become global and crucial infrastructure of education and research throughout the world. Today, education and research are global by their nature and crucially depend on ICT infrastructure as a means for distant collaboration, exchange of ideas, accessing data, information and knowledge and delivery of products and results to customers and users [3].

Analyzing today's needs of academic and research community in the field of ICT, we can recognize the following groups of demands:

\section{A ICT Infrastructure}

\section{A1 Computer Network and Internet access}

High capacity broadband networks, based on achievements of the newest communication technology, with performances and characteristics that are usually commercially unavailable on general markets and commodity access to global network (Internet) are essential prerequisites for modern scientific work and education process.

Day-to-day operations of such networking infrastructure, as well as development and up- grading of this infrastructure highly depend on the existence and efficiency of the Network Operations Center (NOC), that should be in charge of development and maintenance of networking facilities and services.

\section{A2 High Performance Computing}

High performance computing capabilities are still important for a large set of scientific and research projects. Because of their high price, high performance computing resources are sometimes unavailable or insufficiently (in terms of capacity/performance) available at local sites and should be "rented" or collected from other institutions or centers.

Advanced computing is usually performed on supercomputer mainframes, but also on computational clusters and, looking forward, on grid-based computational structures [5], built from less expensive and standard computational modules. Modern business models, such as "on demand computing" should also be considered within academic and research community to satisfy common high performance computational needs.

\section{A3 High Capacity Data Storage and Information Retrieval Systems}

Besides computational power, education or scientific processes, as well as operation of communication, computation or information infrastructure, are impossible or inefficient without adequate high capacity storage devices.

Those devices should allow high-speed storage and retrieval of large quantities of scientific (e.g. experimental) data or information (e.g. bibliographical or educational).

\section{A4 Application Development and Hosting}

Operation of modern ICT infrastructure today highly depends on the existence and efficiency of information and directory infrastructures, built as middleware layer and usually referred to as authentification, authorization and accounting infrastructure (AAAI).

Scientific work and higher education are impossible today without access to a variety of general and specialized information systems and databases. Functioning of universities and institutes relies on business information systems that support scientific, education and other corporate business processes. 
All mentioned information systems and applications should be implemented, reliably hosted and continuously maintained in a professional way.

\section{A5 Data Security and Availability}

Although reliability and availability of ICT infrastructure have not been known as first priority need of an academic community, we should expect change in this field, because of high impact of ICT on overall system performance and quality.

Questions such as disaster recovery (for data or system functionality), efficient, flexible and user-friendly backup and restore procedures, data mirroring or security policy definition, maintaining and monitoring, are definitely entering the agenda, even within academic ICT infrastructure.

\section{B Supporting Users of ICT}

\section{B1 Training}

The speed and extent of change in the field of ICT is tremendous. That's why using ICT implies readiness to permanently learn new possibilities and features of ICT, sometimes even if it isn't seen as necessary.

Users expect continuous on-line availability of high quality educational materials, as well as traditional and on-line/distance training in form of traditional courses and hands-on workshops.

\section{B2 Helpdesk Service (End-User Support)}

Success of implementation of ICT and effects of usage of ICT highly depend on the level and quality of user support provided by ICT team.

Because of the human resources involved, enduser support is definitely one of the biggest challenges in the area of ICT. It should be carefully planned and implemented as integral part of overall ICT system.

\section{B3 Specialized ICT Support and Consulting}

In addition to general end-user support, there is a continuous need for different types of specialized support or consulting in such areas as system and network administration, special purpose software usage, introducing of ICT to scientific and/or education processes etc.

We can conclude that in the next period we should expect nothing but the growth (in terms of quantity as well as variety) of needs of academic and research community in the field of ICT. Increased pressure on ICT teams and budgets will also result from increased correlation between overall results and effectiveness of academic and research community and capacity, reliability, availability and scalability of ICT infrastructure.

\section{University Computing Centers - Focal Points of Academic ICT Infrastructure}

For many years university computing centers (UCC) were "sanctuaries" where users would physically come or eventually approach terminal network to satisfy their computational needs. Entering a computing center building was usually comparable with visiting a building or object from the future world. People in white lab-coats, managing computers and being interfaces between computers and endusers, and rooms with "exotic" computational equipment with thousands of blinking lights fascinated common users for many years.

With time, computers stepped out of computer center buildings and computer rooms, barriers between computers and users were pulled down. In the era of distributed computing and following the "distribute-and-access-anythingover-the-network" paradigm we reached the stage where it seemed as if computing centers had no meaning and no future. It was the time when users tended to keep computing and communication equipment just "at hand" and maintain, when it was "really necessary", those equipment by themselves. The only reasonable "excuse" for the existence of very few computing centers was provision of supercomputing resources.

But, the last 3-5 years have brought significant changes in users' behavior and perception of developing and maintaining ICT infrastructure.

It became obvious that highly distributed computational architectures and networking structures do not operate reliably without adequate nodes and professional maintenance and support provided by centers of ICT knowledge and excellence. Consolidation of servers and data storage and collocation of consolidated servers in adequately equipped data centers are today's answers to costly maintenance of numerous 
servers and to inappropriate scalability of "newserver-per-new-functionality" approach to satisfying the increasing ICT needs.

In view of these new trends and approaches to ICT infrastructure development and maintenance and considering current positions, plans and strategies of university computing centers or services worldwide, we can foresee the following potentials and possible roles of computing centers in academic and research community in the future:

\subsection{UCCs as Nodes of Next Generation Networking Infrastructure}

We have already mentioned advanced needs of academic and research community in the field of high capacity broadband networks, based on the achievements of modern information and communication technology.

Today, there are many national and international projects aimed to build next generation of networking infrastructure, which is not commercially available on the market, such as Internet2 [1] or TeraGrid [7] in the USA or GEANT [6] and DataGRID [8] in Europe. Development and operation of such networks highly depend on collaboration and efficiency of local academic computing centers or services that serve not only as advanced and competent users of infrastructure, but also as NOC or part of distributed NOC of these networks.

Advantages of UCC as NOC or network POP (point of presence) are usually derived from their tradition in providing 24/365 (24 hours / 365 days per year) ICT service, from adequately equipped and secured buildings, from outstanding experts and skilled, highly professional teams usually gathered around state-ofthe-art ICT projects.

UCCs are not only ideal hosts of NOCs or POPs of advanced national or international academic and research networks. The role of UCC is also to plan, build and maintain campus and/or metropolitan area networks, as well as local networking infrastructure, which become more and more complex and demanding in terms of scale, but also in terms of involved technology and variety of supported user applications.

Last, but not least, the role of UCC is to assist users in choosing and consuming commodity access to global network (Internet), usually purchased on the market.

\subsection{UCCs as Computing and Data Centers}

Development of personal, desktop computers allowed us to celebrate, for some period of time, the notion of "bringing mainframe performance to every desktop".

Although we really are continuously getting mainframe performance on our desktops, we are at the same time witnesing permanent growth of a set of more advanced applications and users needing even more sophisticated performance. New paradigms of advanced computing were born, based on the idea of clustering comparatively ordinary computing resources into high performance computing structures. Extending this approach over the high-speed networks we are coming to the idea of computational and information grid as computing and information infrastructure of tomorrow. UCC is the logical place to locate "building blocks" of clusters and Grid, as well as classical mainframe-based high performance or supercomputing facilities (if available in some community). UCCs are competent enough to bring together, administer and maintain complex high-performance computational structures.

UCCs are also ideal places for server farms, consolidated servers and high performance storage devices and systems, which are essential parts of any advanced ICT infrastructure today.

UCCs are ideal places to implement and run important applications and information services, which are crucial for overall academic community functioning, for processes of education and research or for operations of ICT infrastructure itself.

Reliable central backup and/or mirroring functionality, and especially disaster recovery (at data or functionality level) are the options which can be adequately implemented only within UCC.

Once again, predetermination of UCCs for performing the mentioned functionalities is derived 
from their routine in providing 24/365 ICT service, from adequately equipped and secured buildings to outstanding experts and skilled, highly professional teams.

\subsection{UCCs as Knowledge, Education and Support Centers}

There is no doubt that success and effectiveness of ICT usage primarily depend on availability, quality and efficiency of support to the users of ICT [2].

Local support teams are one of the key elements in overall support system, representing the first line of the support chain, working just near end-users, reacting to and serving their primary needs. Operations of local support teams can be dramatically improved and made much more efficient if local teams are assisted by dedicated and highly specialized expert teams, which can be gathered and located at UCC. The knowledge and the expertise power of such teams within UCC comes from their size and hands-on experience in the development and maintaining real infrastructure, but also from their involvement in state-of-the-art technological and research projects.

End-user support in selected highly specialized fields, for example, statistical or simulation methods and tools or particular proprietary or public/free/open software helpdesk can be resourcefully organized within UCC.

Training and education is another important element in enabling users to effectively use and implement ICT. In the world of rapid changes in technology, tools and infrastructure, education and training are not only continuous need of the users, but also continuous occupation for ICT managers and supporting teams. Preparing, refreshing and delivering courses and workshops are among their major and resource-demanding activities. One of potential roles of UCC is to organize and provide continuous development and availability of high-quality educational materials in different forms.

UCC is a rational point to develop and implement smart educational environments built on modern trends of pervasive computing and to organize and deliver advanced and/or specialized educational programs and training (e.g. training for system engineers or information system administrators or "training the trainers" programs for educators in local ICT teams).

Another side of the UCC involvement in education is to implement and/or provide support to massive use of Internet/web in education, including on-line courses.

In the era of continuous education and growing demand for expert support, UCCs are not only focal points of communication and information infrastructure of academic and research community, but they are also becoming important providers of high-quality learning content and efficient and professional support.

\section{University Computing Centre (SRCE), University of Zagreb - 30 Years of Leading in Implementation and Usage of the Newest ICT}

University Computing Centre in Zagreb (SRCE) was founded in 1971 [4] with the aim to serve as central institution for development, implementation and promotion of information technology within academic and research community in Croatia. The scope of activities at that time was defined even broader, and SRCE was expected to play the leading role in "computerization" of all Croatia.

Looking backward we can say that most of those expectations have been fulfilled. During the past thirty years SRCE was an important resource of all Croatian universities and overall Croatian scientific and research community. Newest information technologies and significant computational resources, implemented in SRCE, were continually accessible to users, initially by means of SRCE terminal network that was built all over Croatia, parallelly with the establishment of central computing resources in the SRCE building in Zagreb. At the very beginning of the 90s SRCE was a place where national academic and research network (CARNet) was born and since then SRCE has been CARNet's national network operations center. SRCE is responsible for CARNet's day-to-day operations, but also for administering and functioning of Croatian top level (.hr) domain and Croatian Internet eXchange (CIX) and hosting GEANT PoP in Croatia. 
Over the past thirty years a number of information systems and services of national importance were developed and implemented by SRCE. Most of those systems are serving the needs of academic community, but some of them (e.g. information systems supporting sport events) have achieved national and even international recognition. SRCE is permanently the place where the newest methods in software engineering and computation are tested or implemented in practice.

Courses and workshops prepared and delivered by SRCE have thirty years of tradition: More than 3000 students and teachers attend these programs every year. In cooperation with CARNet, first "train the trainer" programs where developed and delivered in the mid 90s. SRCE is also well known for its general helpdesk for end-users, as well as for specialized referral and support centers (e.g. Helpdesk for system administrators or Statistics and SAS referral center).

According to its today's mission, SRCE contributes to the leading role of the academic community in the development of information society in Croatia by implementing the latest information and communication technologies, providing a quality support and education system for the users of ICT and through the acquisition and dissemination of professional knowledge.

Organized in five "production" departments (networking, computing and system administration, information services and applications, education and user support, special programs) SRCE is delivering to its users more than thirty different products and services. Some of these products are the core products, around which we are planning future SRCE activities:

(a) Network operations center (NOC) - monitoring, development and maintenance of the academic and research network;

(b) Center for cluster and grid technologies common computational and knowledge resource of Croatian academic community;

(c) Collocating and maintaining common consolidated servers and high performance data storage systems;

(d) Developing, hosting and maintaining directory and AAA services, as well as large scientific data bases and information retrieval systems; (e) Hosting and maintaining university business applications and business information systems;

(f) Disaster recovery, backup and mirroring service for academic application providers or important information systems;

(g) Educational center with technologically advanced and smart environment;

(h) Center for implementation and support of Internet/web-based training and research;

(i) Center for support, education and certification of local ICT teams;

(j) Helpdesk services for end-users;

(k) Referral centers for joint purchase of academic licenses of proprietary software, distribution and support for such software;

(1) Referral centers, specialized helpdesks and consultancy in different fields of ICT expertise.

Growing needs of academic community, thirty years of tradition and professional experience, achieved results and successfully realized projects, current responsibilities and products, advantageous infrastructural position and outstanding teams of skilled experts are good guarantees of further advancement and development of SRCE as a focal point of ICT infrastructure at the University of Zagreb, as well as of the overall ICT infrastructure of academic and research community in Croatia.

\section{Conclusion}

After the period of doubts in purpose, rationality and potentials, we've entered the new era in which demands and expectations from university computing centers or centralized university computing services are pushed up to the new frontiers. This reinforcement is caused by the fact that ICT today is not only a resource for computing, but also primarily a vital basic infrastructure for any modern education or research process.

University computing centers (or services) are expected to provide variety of networking, computing and educational services to academic and 
research community, that can be divided in three major groups:

(a) Network (WAN; MAN; LAN) operations management, monitoring and maintenance;

(b) High performance computing and high capacity data warehousing, reliable information management and data provision;

(c) Enabling users, by provision of extended range of forms and levels of support and training.

Although rapid advancement of ICT and development of ICT market have forced UCCs to share, or even to give up some of their roles, academic and research community still manifests advanced needs and specific demands on ICT, that can be efficiently and cost-effectively satisfied only within academic community and by resources available within that community.
Received: June, 2003 Accepted: September, 2003

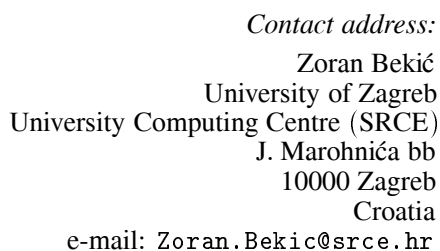

ZORAN BEKIĆ received his B.Sc. and M.Sc. degrees in applied mathematics and computer science from the Lomonosov State University, Moscow, Russia in 1981 and 1984 respectively. Since 1982 he has worked at different positions at University Computing Centre (SRCE), University of Zagreb and is currently the director of SRCE. His basic research interests are in the field of computer architecture, database engines design and simulation modeling. His recent professional activity was in the field of management of ICT projects and ICT infrastructure and in the field of organizing information services and user support He has authored or co-authored more than 40 research and professiona papers.

\section{References}

[1] About Internet2; 2003. http://www . internet2. edu/about/aboutinternet $2 . \mathrm{html}$ [04/25/2003].

[2] BEKIĆ Z., Organizing Information Services and User Support at National Level, in: Proceedings of the $1^{\text {st }}$ NATO / CEENet Workshop on Network Policy; 1997 May 29-31; Tartu, Estonia, pp. 95-100.

[3] BeKić Z., GoJŠÍ́ J., PALE P., The Role and Strategy of an Academic and Research Network in a Developing Country, Computer Communications 2003; 26(5): pp. 460-464.

[4] Budin L., Jurisic-Kette, W., Momirovic, K., PeRUSKO, U., POZAR, H., Simovic, V., STEFANINI, B. TURK, S., SRCE-University Computing Centre, Zagreb: From Project To Realization (in Croatian), in: Proceedings of the $1^{\text {st }}$ International Symposium Computer at the University; 1974 October; Zagreb, Croatia. Zagreb: SRCE University Computing Centre, University of Zagreb; 1974. p. A1.

[5] Foster I., Kesselman C., The Grid: Blueprint for a New Computing Infrastructure, Morgan Kaufmann; 1998.

[6] Introducing GÉANT; 2003. http: www.dante. net/geant/about-geant .html [03/26/2003].

[7] REED D.A., Grids, the TeraGrid and Beyond, IEEE Computer 2003; 36(1): 62-68.

[8] The DataGrid Project; 2003. http://web.datagrid.cnr.it/ [02/24/2003]. 